\author{
S. Gatti · T. Brey · W.E.G. Müller \\ O. Heilmayer · G. Holst
}

\title{
Oxygen microoptodes: a new tool for oxygen measurements in aquatic animal ecology
}

Received: 11 October 2001 / Accepted: 13 December 2001 / Published online: 19 February 2002

C) Springer-Verlag 2002

\begin{abstract}
We describe two applications of a recently introduced system for very precise, continuous measurement of water oxygen saturation. Oxygen microoptodes (based on the dynamic fluorescence quenching principle) with a tip diameter of $\sim 50 \mu \mathrm{m}$, an eightchannel optode array, an intermittent flow system, and online data registration were used to perform two types of experiments. The metabolic activity of Antarctic invertebrates (sponges and scallops) was estimated in respiration experiments, and, secondly, oxygen saturation inside living sponge tissue was determined in different flow regimes. Even in long-term experiments (several days) no drift was detectable in between calibrations. Data obtained were in excellent correspondence with control measurements performed with a modified Winkler method. Antarctic invertebrates in our study showed low oxygen consumption rates, ranging from $0.03-0.19 \mathrm{~cm}^{3} \mathrm{O}_{2} \mathrm{~h}^{-1}$ ind. $^{-1}$. Oxygen saturation inside living sponge specimens was affected by flow regime and culturing conditions of sponges. Our results suggest that oxygen optodes are a reliable tool for oxygen measurements beyond the methodological limits of traditional methods.
\end{abstract}

Communicated by O Kinne, Oldendorf/Luhe

S. Gatti $(\bowtie) \cdot$ T. Brey $\cdot$ O. Heilmayer

Alfred Wegener Institute for Polar and Marine Research,

P.O. Box 120161, 27515 Bremerhaven, Germany

E-mail: sgatti@awi-bremerhaven.de

Tel.: + 49-471-48311392

Fax: +49-471-48311149

W.E.G. Müller

Institute for Physiological Chemistry,

Dept. "Applied Molecular Biology",

Johannes Gutenberg University,

Duesbergweg 6, 55099 Mainz, Germany

G. Holst

Max Planck Institute for Marine Microbiology,

Celsiusstraße 1, 28359 Bremen, Germany

\section{Introduction}

Oxygen consumption rates have been measured with a variety of methods. In spite of the multitude of available methods there are still experimental conditions in which oxygen measurements are very difficult if not impossible (Wilson et al. 1993). Consequently, efforts to develop new sensors and new methods are still ongoing. Today polarographic oxygen sensors (after Clark 1956; hereafter called POS) and chemical procedures developed from the Winkler method (Winkler 1888) are most commonly applied to measure oxygen content in water. While suitable in many experimental situations, measurements at low temperatures, of low oxygen consumption rates, of sediment oxygen profiles with high spatial and/or temporal resolution and of oxygen saturation inside living invertebrates are often difficult to perform with these techniques. POS have often been used successfully in marine sciences, primarily because of high temporal resolution facilitated by the fast response times of the sensors, typically $\sim 1 \mathrm{~s}$ for microPOS (Revsbech et al. 1983). However, POS give rise to five major problems. (1) They tend to drift after calibration. The underlying assumption that drift between two consecutive calibrations is linear may not be valid and may cause considerable errors especially in experiments lasting several hours to a few days. (2) POS are not suitable for measurements at low temperatures (i.e. near or below $0^{\circ} \mathrm{C}$ ) because of prolonged response times and decreasing stability (Peck and Uglow 1990). (3) The POS themselves consume oxygen and can thus only be used in setups with constant stirring. Oxygen consumption by the POS can affect results substantially, especially when the oxygen consumption rates of the specimens are very low. The problem of oxygen consumption by POS has, to some extent, been ameliorated by the introduction of micro-POS (Revsbech et al. 1983) and the pulsing technique (Langdon 1984). Both variations of the method reduce the amount of oxygen consumed by sensors. (4) Mechanical fragility of the sensor 
tip and the covering membrane severely impede use in sediments and inside living tissue. Finally, (5) POS are subject to an aging process: even if unused, they cannot be stored for long periods of time after manufacturing (e.g. storage time for MasCom micro-POS is $\leq 6-8$ months according to the manufacturer's product information; MasCom, Bremen, Germany, http://www.mascomms.de).

The original Winkler method (Winkler 1888) has been subjected to several modifications, primarily aiming at higher precision (see Bryan et al. 1976). The equipment needed is inexpensive and it can be used in the field, wherever a stable power supply is available. However, analysis of samples is laborious (requiring 3-5 min sam$\mathrm{ple}^{-1}$ ), and resolution in time is impeded by the necessity of regular sample-taking (Roland et al. 1999). Options for further automation of the procedure are limited.

Problems concerning precision, applicability under low temperature conditions and mechanical fragility have also been overcome by couloximetry (Peck and Uglow 1990). Results are as accurate, precise and independent of temperature as those obtained by the microWinkler method. Sample volume for one analysis is much smaller $\left(25 \mathrm{~mm}^{3}\right.$ for couloximetry vs. $1 \mathrm{~cm}^{3}$ for micro-Winkler), but the equipment needed is more expensive and more difficult to set up and handle. While being very precise, the micro-Winkler technique and couloximetry have the common disadvantage of low temporal resolution, as single samples have to be analyzed separately.

Oxygen microoptodes (measurements based on dynamic fluorescence quenching) were introduced to aquatic sciences by Klimant et al. (1995), who documented that microoptodes do not consume oxygen. Hence, a zone of oxygen-depleted water around the tip cannot develop. So microoptodes can be used in experimental systems without stirring the medium (e.g. inside tissue samples). Drift is assumed to be negligible. The high mechanical stability of the luminophore matrix offers the possibility to insert optodes into sediment and also into living tissue (Stefansson et al. 1989). Data obtained by microoptodes have the same accuracy and precision as data obtained by mini- or micro-POS (Klimant et al. 1995; Glud et al. 1999). A microoptode array for parallel operation of eight optodes and suggestions for its potential applications were introduced by Holst et al. (1997). The array was further optimized by PreSens (Neuburg, Germany, http://www.presens.de). Precision and reliability of oxygen microoptodes have been well documented in a number of papers (e.g. Wolfbeis 1991; Glud et al. 1999; Stokes and Somero 1999, and references therein). Whereas microoptodes have been successfully applied in the biomedical field, they have not yet been widely adopted in aquatic ecology. We present here two examples of practical use of microoptodes in systems where measurements with the commonly used POS would have been impossible.

Polar invertebrates usually have low oxygen consumption rates (e.g. Clarke 1983; Chapelle et al.
1994; Chapelle and Peck 1995; Peck and Conway 2000, and references therein). When comparing sessile invertebrates with motile fauna we can expect a considerably lower metabolic activity and thus extremely low oxygen consumption rates. Hence, a method is required that is: (1) very sensitive and (2) does not exhibit any drift.

It is possible to grow primmorphs (well-defined sponge cell aggregations surrounded by a dermal membrane) from cell aggregations of the sponge Suberites domuncula (see "Materials and methods" section). However, growth becomes limited or ceases when primmorphs reach a diameter of 3-4 mm (Müller et al. 1999). In spite of attempts with a variety of culturing methods, the reasons for recess of growth remain unknown. Pumping structures such as choanocyte chambers have not yet developed in small primmorphs. It is possible that diffusion through the tissue does not provide enough gas exchange and growth is inhibited by lack of oxygen supply. To test this hypothesis we measured the oxygen content inside primmorphs reared under a variety of conditions and inside adult sponges, utilizing the described features of stability and high temporal resolution of oxygen microoptodes.

\section{Materials and methods}

The system used for our experiments is summarized in Fig. 1. Technical details can be found in Holst et al. (1997) and Klimant et al. (1997). Oxygen acts as a dynamic fluorescence quencher of a luminophore, which is immobilized in a polymer matrix. Intensity, lifetime, and modulation of phase angle of the fluorescence signal are influenced by the number of oxygen molecules present and can be measured.

As fluorescence intensity is affected by several additional factors (e.g. length, bending and micro-bending of the cable) phase angle modulation was used to calculate oxygen saturation in the water.

The sensor consists of a fiber optic cable supplied with a standard glass fiber plug to connect it to the optode array. Technical specifications of microoptodes as provided by the manufacturer are given in Table 1. The sensor end of the cable can be tapered to various tip diameters and is then coated with a ruthenium-IIluminophore-complex (details of sensor tip mounting are shown in Fig. 2). Light is emitted from one common light source (blue-lightemitting diode) through an optical switch to each of the eight sensors sequentially. The resulting fluorescence signal is detected and enhanced by a photomultiplier.

Depending on the number of sensors connected to the array, each sensor performs a measurement every 1-2 min. All data (time, sensor number, phase angle, oxygen saturation and a control for background lighting) are transmitted directly to a computer for continuous data registration. Two-point calibrations were performed with all microoptodes connected to the same water reservoir. Nitrogen bubbling and air bubbling were used to calibrate the $0 \%$ and $100 \%$ air saturation points, respectively. After stabilization of the phase angle, measurements were continued for at least $10 \mathrm{~min}$. Signal variation after stabilization of the calibration signal was documented to facilitate an estimate of drift during and in between experiments. Both calibration points were checked twice with a modified Winkler method (according to WOCE guidelines; Culberson 1991; Dickson 1996). To estimate precision and accuracy of the method we compared ten consecutive measurements as performed by each sensor using water from the calibration procedures (i.e. water with $0 \%$ and $100 \%$ air saturation). This was repeated prior to each experiment.

Two types of experiments were performed. (1) Respiration experiments: Oxygen consumption rates of Antarctic invertebrates 
Fig. 1. Schematic diagram of the system used in both types of experiments. Optical cables are connected with standard glass fiber plugs to an eight-channel optode array $(A)$. All data are transmitted directly to a computer $(B)$ for continuous registration. For better protection of sensor tips, sensors were kept in a sensor block $(C)$ during the first set of experiments. Air and water tightness of syringes in the sensor block were ensured by double o-rings for every syringe (not shown). Arrowheads indicate direction of water flow (open from respirafilled away from sensors to pumps). For the second set of experiments the sensors were inserted into the sponges directly instead of being kept in the sensor block. Details of sensor mounting in syringe are enlarged in Fig. 2 tion chambers towards sensors;

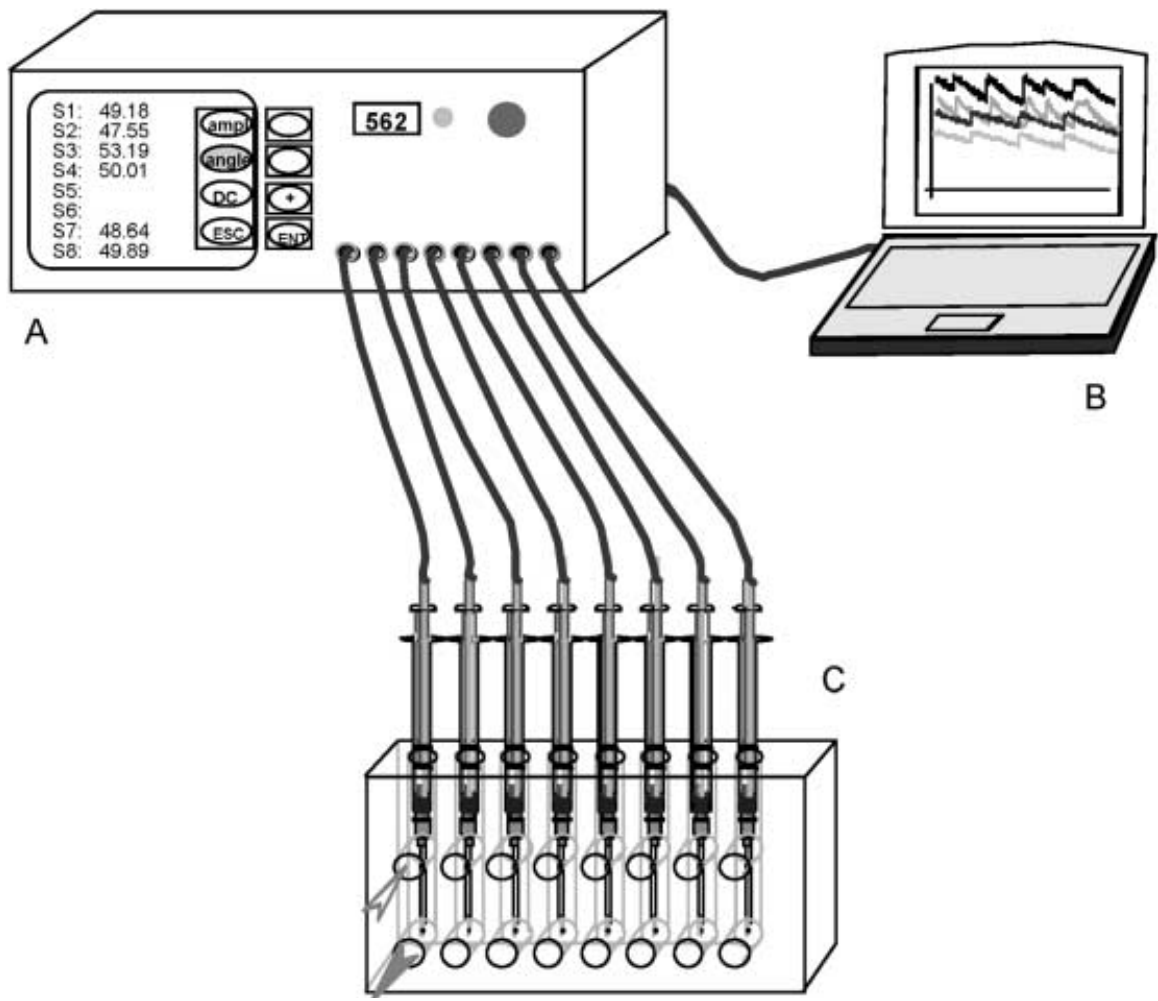

[sponges: Cinachyra antarctica (Carter, 1872) and Stylocordyla borealis (Lovén, 1868); scallop: Adamussium colbecki (Smith, 1902)] were determined from decreases of oxygen saturation in an intermittent flow system. (2) Oxygen content inside living sponge tissue: Oxygen saturation inside living sponges [Suberites domuncula (Olivi, 1792)] was measured and compared to simultaneously measured oxygen saturation of the water surrounding the sponge.

\section{Respiration experiments}

All respiration experiments were performed on board R.V. "Polarstern" (during expeditions ANT XV/3 and XV/4 in 1998 to the Weddell Sea, Antarctica) in a temperature-controlled room at near-ambient water temperature $\left(-0.5^{\circ} \mathrm{C}\right.$ to $\left.+0.5^{\circ} \mathrm{C}\right)$ and salinity $(\mathrm{S}=34)$. Respiration chambers were immersed in a larger volume of water $\left(200 \mathrm{dm}^{3}\right)$ to maintain stable temperature during periods of automated defrosting cycles in the temperature-controlled room. Unfiltered seawater was used, as pilot studies had shown that both sponge species ( $C$. antarctica and $S$. borealis) had tightly closed oscula when kept in filtered seawater. As all specimens were taken from water depths below the euphotic zone, all experiments were carried out in the dark. One control chamber (i.e. with no animal) was run in parallel to each experiment. After the first initial calibration, calibration points were checked regularly at the beginning of a new experiment. Daily blank controls of the optode array (with all sensors disconnected) were performed to control for internal (i.e. inside the optode array) ambient light conditions (for details see manual of eight-channel optode array, PreSens, http://www. presens.de).

We used respiration chambers of variable volume (Fig. 3) to be able to adjust chamber size to a wide variety of animal sizes. Chambers were equipped with a movable bottom lid, which could be pushed into the cylindrical respiration chambers to reduce the water volume around the animal. Air and water tightness were ensured by double o-rings between the cylindrical chamber and the lid. Chamber volume was adjusted to specimen size once prior to each experiment and then kept constant for the duration of one experiment. Control chambers were adjusted to a similar volume as experimental chambers. Measurements started immediately after
Table 1. Technical specifications of microoptodes used in our experiments (as provided by the manufacturer, PreSens, Germany)

\begin{tabular}{ll}
\hline Measuring range & $0-672 \mathrm{hPa}(0-150 \%$ air saturation $)$ \\
Accuracy at: & $\pm 0.2 \mathrm{hPa}$ \\
$5 \mathrm{hPa}$ & $\pm 0.5 \mathrm{hPa}$ \\
$50 \mathrm{hPa}$ & $\pm 3.0 \mathrm{hPa}$ \\
$219 \mathrm{hPa}$ & $30-50 \mu \mathrm{m}$ \\
Tip diameter & $2-3 \mathrm{~s}$ \\
Response time &
\end{tabular}

closing of the chambers, without allowing time for acclimation of the animals to chambers, as we wanted to compare initial oxygen consumption rates with those obtained in subsequent experimental cycles. To ensure a constant water flow through experimental chambers, all chambers were connected to an intermittent flow system. Water was pumped from the respiration chamber to the sensor and back to the respiration chamber with two, four-channel peristaltic pumps, with nominal maximum capacity of $1.7 \mathrm{dm}^{3}$ $\min ^{-1}$ channel $^{-1}$ (Masterflex: precision pump, model 7520-47). Highest pumping rates were used for largest chamber sizes. A set of preliminary experiments with ink showed quick and even mixing inside all the various sizes of chambers we used.

Circulation through the chamber was opened for $100 \%$ saturated water when oxygen saturation fell below $80 \%$ inside the chambers and was closed again when saturation was back at $100 \%$. Depending on the availability of respiration chambers and of invertebrate specimens, every individual was allowed to go through three to seven repeated cycles of opening and closing of the system. Cycles lasted 2-14 h each. For calculation of total oxygen consumption in a respiration chamber, linear regressions of oxygen saturation versus time were calculated for all measurements in one cycle. Cycles shorter than 3 h (i.e. < 90 single measurements) were excluded from the analysis. Visual inspection of the data of cycles with a regression coefficient $r^{2}<0.9$ revealed unusual peaks and troughs in oxygen saturation data, possibly caused by strong defrosting cycles in the cool room. So those cycles were also excluded from further analysis. Visual inspection of the remaining data sets (with a regression coefficient $r^{2}>0.9$ ) revealed no peaks or 


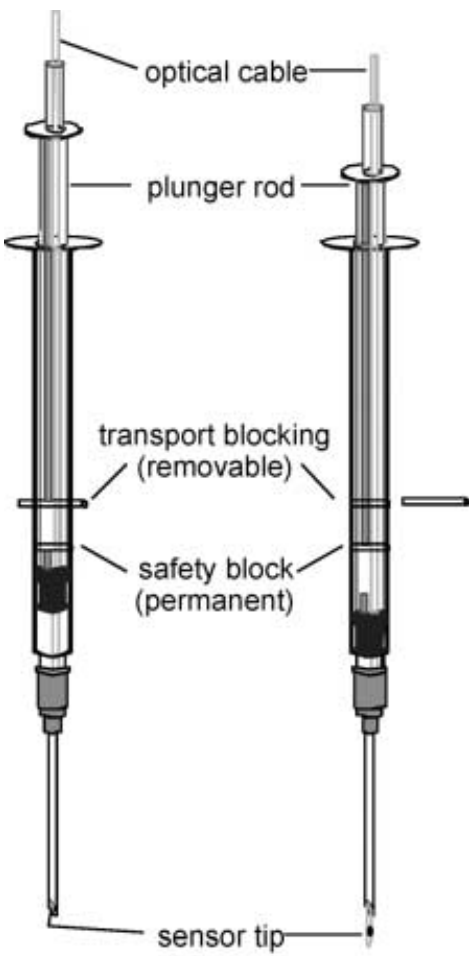

(A)

\section{(B)}

Fig. 2. Schematic drawing of microoptode mounted in a standard $1 \mathrm{~cm}^{3}$ syringe. The optical cable is permanently fixed to the plunger rod. By pushing or pulling the plunger rod the sensor tip is retracted into the needle tip ( $A$, protected position for transportation) or protruding from the needle tip ( $B$, measuring position). A gap in the stabilizing structure of the plunger rod (hatched bar) and a permanent safety block determine both end points of plunger rod movement and thus maximum retraction or protrusion of sensor tip (Please note: the sensor is also capable of measuring oxygen saturation when inside the needle. However, as water exchange within the needle is limited, results obtained from such measurements would be subject to prolonged response times and would not reflect the true oxygen content within surrounding water masses.)

troughs that would affect linear regression. After every experiment total water volume in each respiration chamber, including adjacent tubing, was determined by emptying the chamber contents into a measuring cylinder. Ammonia was measured in each chamber to control for waste products using a test kit by Merck (Merckoquant for ammonium). After experiments on the ship were completed, specimens were frozen $\left(-30^{\circ} \mathrm{C}\right)$. To determine wet mass (WM), dry mass (DM) and ash-free dry mass (AFDM) sponges were oven dried for $24 \mathrm{~h}$ at $100^{\circ} \mathrm{C}$ and ignited for $24 \mathrm{~h}$ at $500^{\circ} \mathrm{C}$ (Paine 1964). Scallops were oven dried for $24 \mathrm{~h}$ at $80^{\circ} \mathrm{C}$ and ignited for $12 \mathrm{~h}$ at $500^{\circ} \mathrm{C}$. Data for sponges' ash mass were corrected for water loss from the spicule matrix during burning, as documented by Dayton et al. (1974). Mass-specific oxygen consumption rates $\left(\mathrm{O}_{2 \text { cons }}\right)$ were calculated with the formula:

$\mathrm{O}_{2 \text { cons }}=\frac{\left(\mathrm{sat}_{t=0}-\mathrm{sat}_{t=60}\right) / 100 \times \mathrm{O}_{2 \mathrm{sat}} \times V-\mathrm{O}_{2 \text { contr }}}{\mathrm{bm}}$

where $\mathrm{O}_{2 \text { cons }}$ is the mass-specific oxygen consumption rate $\left(\mathrm{cm}^{3} \mathrm{O}_{2}\right.$ $\mathrm{h}^{-1} \mathrm{~g}^{-1}$ AFDM); $\mathrm{O}_{2 \text { sat }}$, the oxygen content of seawater saturated with oxygen $\left(\mathrm{cm}^{3} \mathrm{O}_{2} \mathrm{dm}^{-3}\right.$ seawater) computed according to Benson and Krause (1984); sat $t_{t=0}$, oxygen saturation (\%) at beginning of experiment; sat $t_{t=60}$, oxygen saturation (\%) after $60 \mathrm{~min}$, as calculated from linear regressions of each cycle; $V$, the true water volume of the respiration chamber and tubing $\left(\mathrm{dm}^{3}\right)$ (i.e. corrected
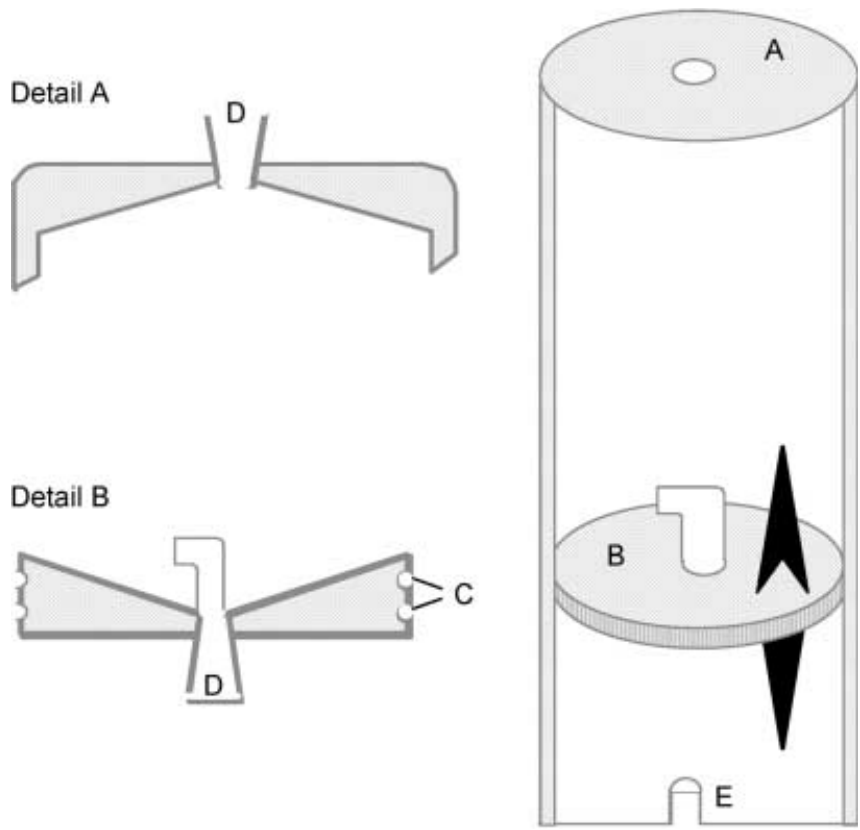

Fig. 3. Respiration chambers with variable volume. The top lid $(A)$ of the chamber is fixed. The bottom lid $(B)$ is movable inside the chamber to adjust chamber volume prior to an experiment. Air and water tightness are ensured by a set of two o-rings between bottom lid and chamber wall (within the two notches $C$ ). Inflow of water through the tube connector $(D)$ of the bottom lid $(B)$, outflow of water through the tube connector of the top lid $(A)$. Notch $(E)$ within the chamber wall allows the tubing to be passed to the pumps when the chamber is standing in an upright position (Please note: both lids slope towards the central hole to avoid the trapping of air bubbles.)

for animal volume); bm, body mass of the animal (AFDM); and $\mathrm{O}_{2 \text { contr }}$, oxygen consumption attributed to bacteria and microheterotrophs inside the experimental chamber.

Oxygen consumption in control chambers was attributed to bacterial and microheterotrophic respiration. It can be assumed that growth of this size fraction of organisms was similar in control and experimental chambers. We further assume that such growth occurs both along the walls of respiration chambers as well as in the water volume. To be able to include both types of growth we created an artificial factor VA [VA $=V \times A$, where $V$ is the volume of the respiration chamber and tubing $\left(\mathrm{cm}^{3}\right)$ and $A$ is the inner surface area of the respiration chamber and adjacent tubing $\left(\mathrm{cm}^{2}\right)$ ], to which oxygen consumption inside control chambers was fitted. Weighted linear regression (Draper and Smith 1980) showed that VA correlated well with oxygen consumption inside control chambers:

$\mathrm{O}_{2 \text { contr }}\left[\mathrm{cm}^{3} \mathrm{O}_{2} \mathrm{~h}^{-1} \mathrm{VA}^{-1}\right]=2.38 \times 10^{-3}+\mathrm{VA} \times 5.00 \times 10^{-8}$

$\left(n=42, R_{\text {adj }}^{2}=0.71, P<0.001\right)$. Oxygen consumption of bacteria and heterotrophs inside experimental chambers $\left(\mathrm{O}_{2 \text { contr }}\right)$ was calculated according to the fitted regression.

\section{Oxygen content inside living sponge tissue}

All experiments with $S$. domuncula were performed at the University of Mainz (Institute of Physiological Chemistry) in November 1999. Experiments were conducted with adult sponges (A) and three different types of primmorphs (P) (Table 2). Adult sponges were taken from the Mediterranean Sea in 1997 and since then have been kept in aquaria. For cultivation of primmorphs some cells were taken from adult sponges and incubated separately in artificial 
Table 2. Suberites domuncula. Sponges and incubation conditions used in the second set of experiments. Primmorphs are cell lumps of $\sim 3 \mathrm{~mm}$ diameter which form some weeks after tissue samples are taken from adult sponges. All sponges were kept in artificial seawater (salinity $=40-42$, temperature $=16-19^{\circ} \mathrm{C}$ )

\begin{tabular}{lllll}
\hline Specimen & Type & Pressurized & Feeding & Antibiotics \\
\hline P1 & Primmorph & No & Beer wort & Yes \\
P2 & Primmorph & No & No feeding & Yes \\
P3 & Primmorph & Yes & No feeding & Yes \\
A1 & Adult & No & No feeding & No \\
A2 & Adult & No & No feeding & No \\
\hline
\end{tabular}

seawater in petri dishes (47 $\mathrm{mm}$ diameter). To avoid bacterial growth, antibiotics were added. After some weeks the cells had rearranged and formed an irregular lump surrounded by a dermal membrane, the pinacoderm (Müller et al. 1999). All primmorphs used in our experiments were of similar size ( $\sim 3 \mathrm{~mm}$ diameter). Type P1 was additionally fed with extra nutrients (beer wort). Type P1 and P2 primmorphs were incubated in stagnant water without flow; type $\mathrm{P} 3$ primmorphs were incubated in a pressurized chamber [1 atm overpressure (Krasko et al. 1999)] at constant flow of $\sim 80 \mathrm{~cm} \mathrm{~s}^{-1}$ through the chamber. The number of available primmorphs was limited by the principal difficulties of cultivating well-defined primmorphs that have developed a pinacoderm (Müller et al. 1999). We had to use primmorphs reared under a number of different conditions to achieve a maximum number of experiments.

Measurements were performed at a temperature of $\mathrm{T}=19^{\circ} \mathrm{C}$, a salinity of $\mathrm{S}=40$ and atmospheric pressure, without any flow. Primmorphs were usually kept in the same petri dishes used for cultivation; measurements of adults were performed in $2 \mathrm{dm}^{3}$ glass beakers. Additionally P3 was exposed to varying flow speeds in an aquarium. One microoptode was inserted into the sponge specimen, while a second sensor measured oxygen saturation in the water closely surrounding the sponge. Inserting the microoptode initially caused a contraction in adult sponges. After a recovery time of $\sim 15 \mathrm{~min}$, sponges appeared to be in their normal state of relaxation again. To compensate for a possible initial reaction of the sponge to insertion of the optode, every experiment lasted 20 $45 \mathrm{~min}$ (i.e. at least $20 \mathrm{~min}$ of which the sponges appeared in their normal state of relaxation). We assume that adult sponges recovered completely from our experiments as none of them died in the following 2 weeks. Primmorphs, however, died subsequently, as had all other primmorphs after reaching a maximum size of $\sim 3 \mathrm{~mm}$, even when not subjected to experiments.

\section{Results}

For both types of experiments sensors and optode array worked reliably and without any problems. Precision and accuracy were high (Fig. 4), albeit slightly higher for water with $0 \%$ oxygen saturation than for $100 \%$ saturated water. Calibrations were easy to perform and in close correspondence with Winkler measurements (Fig. 5). There was no significant difference between measurements of microoptodes and Winkler control measurements (ANOVA: $100 \%$ air saturation: $n=64, P=0.83 ; 0 \%$ air saturation: $n=64$, $P=0.15)$. Drift between calibrations was negligible (Table 3). Of the four optodes used in respiration experiments only one optode showed significant drift of the $0 \%$ calibration point: $+0.03 \%$ in 93 days. Drift of the $100 \%$ calibration point was slightly larger and

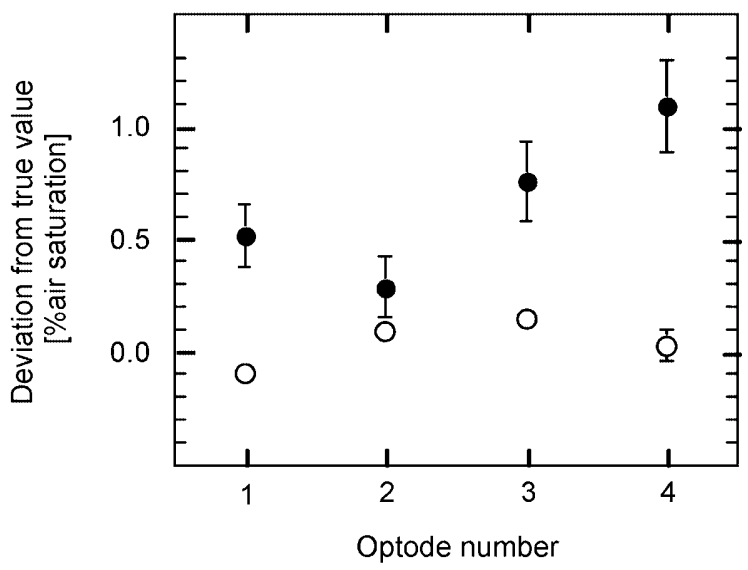

Fig. 4. Precision and accuracy of microoptodes. Precision is given as mean deviation from true oxygen saturation value $(\%$ air saturation) for water of $0 \%$ (open symbols) and $100 \%$ air saturation (filled symbols) for each of the four optodes used during our experiments ( $n=130$ for each sensor and saturation level). Accuracy can be inferred from error bars $( \pm 1 \mathrm{SE})$. Where error bars are missing they are inside the symbol

significant for all but one optode: $-3.0 \%$ to $-3.4 \%$ in 93 days.

\section{Respiration experiments}

Exemplary typical raw data are presented for two individuals of Stylocordyla borealis (Fig. 6). While the circulation was closed, decrease of oxygen content within respiration chambers was continuous and uniform. Variation around linear regressions was minimal for experimental chambers but higher for control chambers. Slope of the decrease of oxygen saturation was uniform within single experiments, i.e. there was no difference in slope detectable that could be attributed to acclimation of animals. After opening of the circulation, the flushing of chambers was quick, the optode-response instantaneous, and usually oxygen levels were back to $100 \%$ air saturation after $10-15 \mathrm{~min}$. For each species of Antarctic invertebrate studied, we show the results of one typical experimental run (Fig. 7A, B). Oxygen consumption rates of the Antarctic sponges ranged between 0.04 and $0.38 \mathrm{~cm}^{3} \mathrm{O}_{2} \mathrm{~h}^{-1} \mathrm{~g}^{-1}$ AFDM and were generally lower than those of the scallop (0.15-0.35 $\mathrm{cm}^{3} \mathrm{O}_{2} \mathrm{~h}^{-1} \mathrm{~g}^{-1}$ AFDM) (Fig. 7B). For all species individual oxygen consumption increased with size of the specimen [increase 3.4-fold for Cinachyra antarctica, 4.1-fold for $S$. borealis and 5.8-fold for Adamussium colbecki, over a size range of $0.09-1.28 \mathrm{~g}$ AFDM (Fig. 7A)]. Mass-specific respiration rates, however, decreased with increasing specimen size for all species (Fig. 7B). Large C. antarctica used $24 \%$ of the amount of oxygen per gram AFDM of small specimens, S. borealis used $33 \%$, and $A$. colbecki, $43 \%$. At the end of each experiment ammonia concentrations in all respiration chambers were below detection limits. The complete sets of results covering the known size range of 


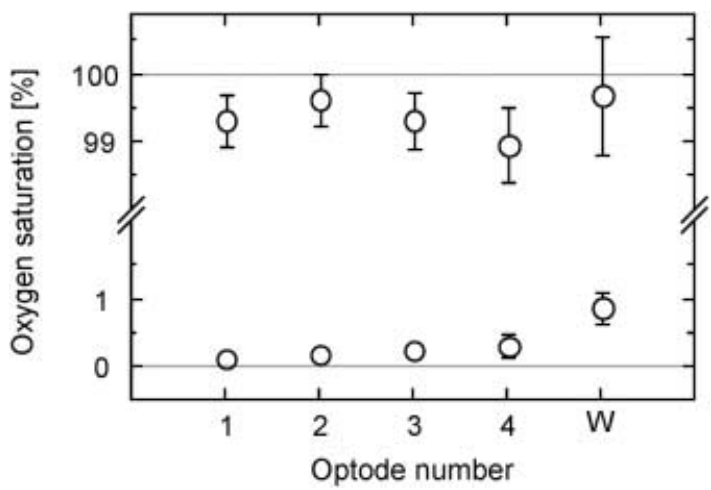

Fig. 5. Comparison microoptode with Winkler measurements. Oxygen saturation as measured by four optodes after approximately $15 \mathrm{~min}$ of nitrogen bubbling (for $0 \%$ calibration point) or air bubbling (for $100 \%$ calibration point). Displayed data are means $\pm 1 \mathrm{SE}$ of experiments performed within a period of 3 months ( $W$ mean of Winkler control measurements). Where the error bars are not shown, they are inside the symbol

each species and ecological interpretations will be presented elsewhere.

\section{Oxygen content inside living sponge tissue}

Saturation around the sponges (control values) varied slightly between measurements (max. SE of control measurements: $\pm 1.42 \%$ air saturation), as there was no water flow or mixing within the petri dishes but sponges did consume oxygen. To facilitate direct comparison between different experiments, all results were expressed as the percentage of oxygen saturation of the surrounding water. Oxygen saturation inside living sponge tissue varied markedly between individuals (Fig. 8). P3 reared in the pressurized flow environment and adult sponges showed highest oxygen saturation values when compared to the surrounding water $(50.8-71.2 \%)$. P1 (no flow, fed with beer wort) showed the overall lowest oxygen saturation inside the tissue (mean oxygen saturation $2.3 \%$ of the surrounding water). P2 (no flow or feeding) had a mean oxygen saturation of $15.0 \%$ of the surrounding oxygen saturation. Even though $\mathrm{P} 3$ had to be taken out of the flow and the pressurized chamber for measurements, mean oxygen saturation in this specimen was 30-fold higher when compared with P1. Additionally, P3 was tested in an aquarium with running seawater. Oxygen saturation inside the primmorph was initially $32.7 \pm 0.49 \%$ of surrounding water (mean $\pm 1 \mathrm{SE}$ ). With the onset of increased flow speed oxygen saturation also increased inside the sponge $(48.3 \pm 0.62 \%$, mean $\pm 1 \mathrm{SE})$. When flow speed was reduced, oxygen saturation inside the sponge dropped instantaneously to $12.9 \pm 0.45 \%$. Adult sponges typically showed low oxygen content at the beginning of each experiment but rising values for about 20 min thereafter. Oxygen content then stabilized between $50 \%$ and $60 \%$ of that of the surrounding water (Fig. 8).
Table 3. Drift of microoptodes in between experiments. Means for each calibration process were Spearman rank correlated with time (days after first experiment). Spearman rank correlation coefficients $\left(r_{\mathrm{S}}\right)$, values of significance $(P)$ and number of experiments $(n)$ are given for each of the four optodes used during respiration experiments. Drift refers to the drift of each optode as calculated from all calibrations over a period of 93 days (n.s. not significant)

\begin{tabular}{lllll}
\hline \multicolumn{5}{c}{ Microoptode } \\
\cline { 2 - 5 } & 1 & 2 & 3 & 4 \\
\hline $0 \%$ calibration & & & & \\
$r_{\mathrm{S}}$ & 0.600 & 0.118 & 0.279 & 0.236 \\
$P$ & $0.025 *$ & 0.659 & 0.297 & 0.378 \\
$n$ & 15 & 15 & 15 & 15 \\
Drift & $+0.03 \%$ & n.s. & n.s. & n.s. \\
$100 \%$ calibration & & & & \\
$r_{\mathrm{S}}$ & -0.574 & -0.745 & -0.679 & -0.490 \\
$P$ & $0.039 *$ & $0.007 * *$ & $0.014 *$ & 0.077 \\
$n$ & 14 & 14 & 14 & 14 \\
Drift & $-2.95 \%$ & $-3.38 \%$ & $-3.36 \%$ & n.s. \\
\hline
\end{tabular}

\section{Discussion}

\section{Respiration experiments}

We measured oxygen consumption rates of three species of Antarctic invertebrates in an intermittent flow system using microoptodes. For all three species, oxygen consumption rates were low $\left(0.04-0.38 \mathrm{~cm}^{3} \mathrm{O}_{2} \mathrm{~h}^{-1} \mathrm{~g}^{-1}\right.$ AFDM). These data are among the lowest oxygen consumption rates ever measured directly (Table 4). Couloximetry is one of the methods that has successfully been used for oxygen measurements of polar invertebrates in several studies (e.g. Chapelle et al. 1994; Chapelle and Peck 1995; Schmid 1996; Brockington 2001; Peck and Veal 2001). The authors gained precision but lost high temporal resolution by utilizing this method. High temporal resolution is obtained with very precise microoptodes. In our experiments drift of the microoptodes at $0^{\circ} \mathrm{C}$ was negligible (max. $3.38 \%$ over 93 days) and distinctly lower than in POS at any temperature (Fig. 9). Moreover, POS drift becomes larger and less predictable with decreasing temperatures, making them rather unsuitable for measuring small changes in oxygen concentration at lower temperatures (Schmid 1996). Oxygen consumption rates of the Antarctic demosponges Isodyctia kerguelensis and Mycale acerata were measured in an open flow system equipped with POS (Kowalke 2000). Unfortunately it was not stated if or how the large drift was accounted for. In light of the known large drift of POS at low temperatures, it must be difficult to: (1) distinguish equilibrium from non-equilibrium states after only $3 \mathrm{~h}$ of adjustment time, when theoretically (Propp et al. 1982) more than $9 \mathrm{~h}$ are needed and (2) to measure oxygen consumption rates that are much lower than the drift.

Open flow systems are highly desirable for laboratory experiments with sponges because, as has been well documented, sponges depend on flow for various biological functions (e.g. Hummel et al. 1988; Leichter and 


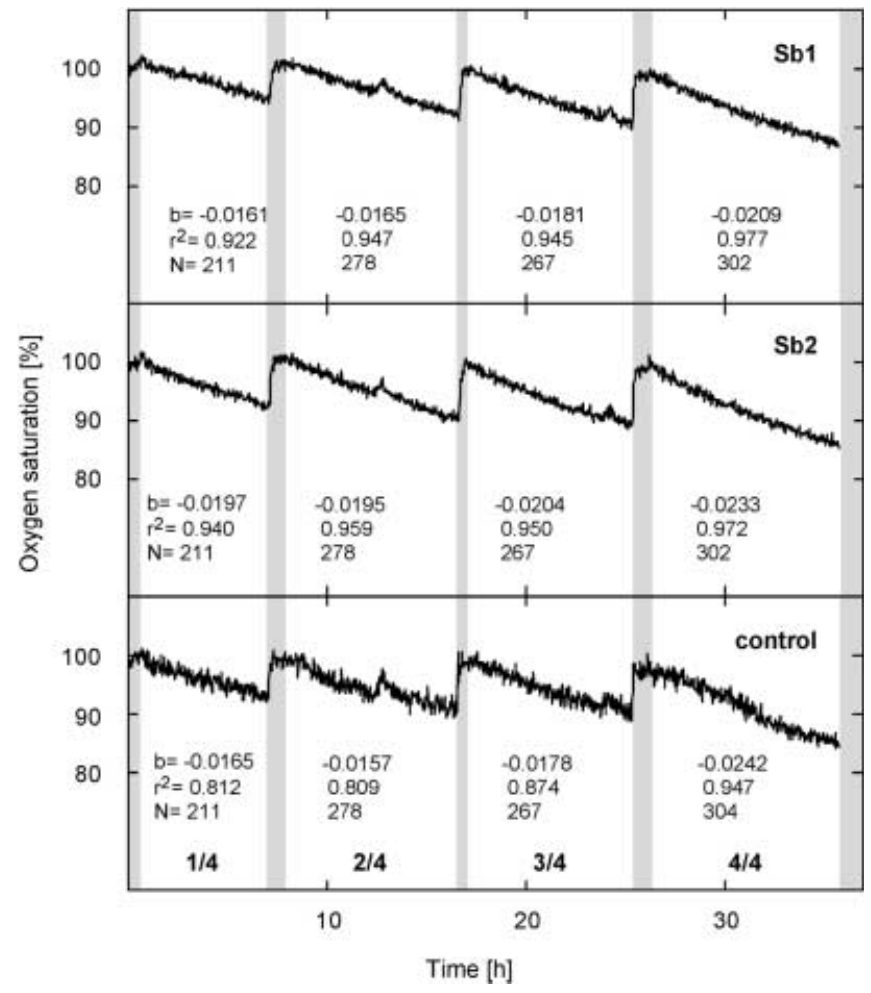

Fig. 6. Stylocordyla borealis. Unprocessed data of respiration experiments of two individuals $(S b 1, S b 2)$ and one control run (gray blocks data were excluded from analysis, e.g. when the system was opened for flushing; white blocks measuring phase, with closed system). Linear regressions were calculated for measuring phases with closed system only. For every cycle the slope $(b)$ of the linear regression, the correlation coefficient $\left(r^{2}\right)$, and the number of single measurements $(N)$ included in the linear regression are given (in this order)

Witman 1997). Also, open flow systems ensure that specimens are exposed to constant oxygen saturation levels near $100 \%$. However, special attention has to be paid to the time required to attain equilibrium between inflow of water with $100 \%$ oxygen saturation and outflow of water from the chamber. On the other hand, small changes in oxygen concentration are easier to detect in closed bottle systems (e.g. Chapelle et al. 1994). Furthermore, no adjustment time is needed when operating a closed bottle system. We decided not to use an open flow system. Times needed for equilibrium adjustment would have been too long for the chamber size $\left(0.2-14.7 \mathrm{dm}^{3}\right)$ we used and the maximum flow speed available. To be able to nevertheless utilize the advantages of an open flow system (constant flow through respiration chambers) and a closed chamber system (very small oxygen consumption rates being easier to detect) we used an intermittent flow system. Regular opening of the chambers and flushing with water from a large reservoir (in our case $200 \mathrm{dm}^{3}$ ) did not only bring oxygen saturation back up to $100 \%$ but also flushed out waste products. Ammonia levels in our experiments were always below detection level.

We could not find a consistent increase or decrease of oxygen consumption rates within experiments, i.e.
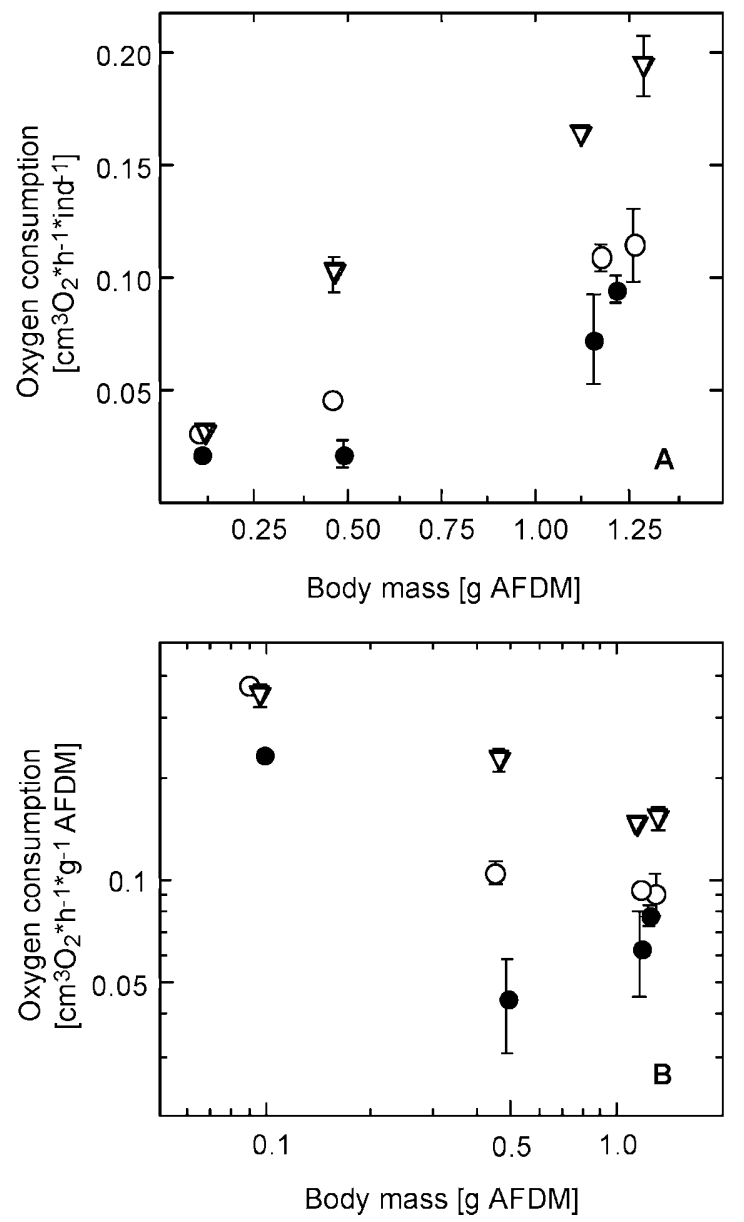

Fig. 7A, B. Antarctic invertebrates. Oxygen consumption rates versus body mass for Adamussium colbecki (open triangle), Cinachyra antarctica (filled circle) and Stylocordyla borealis (open circle) are shown as means $\pm 1 \mathrm{SE}$. Where error bars are not shown they are inside the symbol. A Oxygen consumption rates of individuals $\left(\mathrm{cm}^{3} \mathrm{O}_{2} \mathrm{~h}^{-1}\right.$ ind. $\left.{ }^{-1}\right)$ versus body mass (g AFDM); B mass-specific oxygen consumption rates $\left(\mathrm{cm}^{3} \mathrm{O}_{2} \mathrm{~h}^{-1} \mathrm{~g}^{-1}\right.$ AFDM) versus body mass (g AFDM). Please note logarithmic scales of both axes

sponges did not need an acclimation time for adjustment to the respiration chambers. It has been argued that transferring specimens into respiration chambers causes stress to the animals and temporarily elevated metabolic rates (Peck and Conway 2000). On the other hand, Lampert (1984) argues that it is not clear whether initially higher metabolic rates are an experimental artifact or reflect conditions in the field. In the later case reduced flow speeds in respiration chambers, alterations in light regime or confinement to a respiration chamber itself could cause reductions in metabolism, as observed in later phases of respiration experiments. Both arguments may be valid for certain groups of higher invertebrates, and stress can certainly play an important role in respiration experiments with vertebrates. Our results suggest that sponges do not exhibit such alterations in metabolic rates due to transfer to respiration chambers, as oxygen consumption neither decreased nor increased systematically with duration of the experiments. 


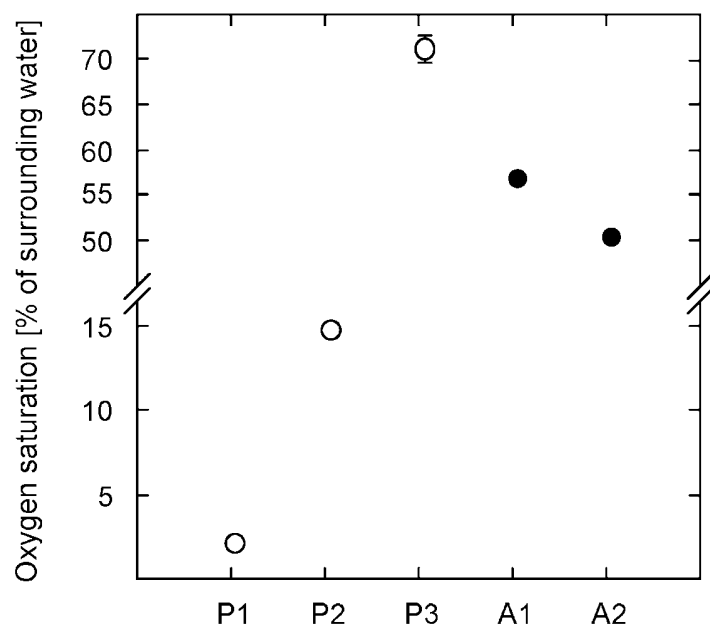

Fig. 8. Suberites domuncula. Oxygen content inside living sponges. Data displayed are means $\pm 1 \mathrm{SE}$ for $10-15$ consecutive measurements (open symbols primmorphs; filled symbols adult sponges; P1 fed; $P 2$ not fed; $P 3$ flow and pressure; $A 1, A 2$ adult sponges). Where error bars are not shown they are inside the symbol. Please note the broken $y$-axis

Data on the oxygen consumption rates of polar sponges are rare. Apart from this study, Witte and Graf (1996) and Kowalke (2000) have provided the only other oxygen consumption rates for polar sponges. Witte and Graf (1996) calculated oxygen consumption data from heat production measurements. Whenever anoxic metabolism can be ruled out (as in the case of polar sponges) heat production data reflect

Table 4. Oxygen consumption rates for cold water invertebrates. Data are minimum and maximum values of the respective study and are given as $\left(\mathrm{cm}^{3} \mathrm{O}^{2} \mathrm{~h}^{-1} \mathrm{~g}^{-1}\right.$ AFDM) or when indicated by asterisk as $\left(\mathrm{cm}^{3} \mathrm{O}^{2} \mathrm{~h}^{-1} \mathrm{~g}^{-1}\right.$ dry flesh mass) [abbreviations of incubation methods/systems: $O$ open flow system; $C$ closed bottle; $I$

\begin{tabular}{|c|c|c|c|c|c|c|}
\hline Taxon & Min. & Max. & Temp. $\left({ }^{\circ} \mathrm{C}\right)$ & $\mathrm{O}_{2}$ determination & $\begin{array}{l}\text { Incubation } \\
\text { method }\end{array}$ & Study \\
\hline \multicolumn{6}{|l|}{ Brachiopoda } & Peck (1989) \\
\hline \multicolumn{7}{|l|}{ Crustacea } \\
\hline Saduria entomon & 0.050 & 0.117 & 0.0 & $\mathrm{C}$ & $\mathrm{C}$ & Schmid (1996) \\
\hline Waldeckia obesa & 0.042 & 0.071 & $0.0 \pm 0.1$ & $\mathrm{C}$ & $\mathrm{C}$ & Chapelle et al. (1994) \\
\hline $\begin{array}{l}\text { Sterechinus neumayeri } \\
\text { Mollusca }\end{array}$ & 0.023 & 0.084 & $-1.8 /+0.5$ & $\mathrm{C}$ & $\mathrm{C}$ & Brockington and Peck (2001) \\
\hline Adamussium colbecki & 0.149 & 0.352 & $0.0 \pm 0.5$ & M & I & Present study \\
\hline Astarte montagui & 0.004 & 0.039 & 0.0 & $\mathrm{C}$ & $\mathrm{C}$ & Schmid (1996) \\
\hline Chlamys islandica & 0.085 & 0.370 & 0.0 & $\mathrm{C}$ & $\mathrm{C}$ & Schmid (1996) \\
\hline Clinocardium ciliatum & 0.050 & 0.057 & 0.0 & $\mathrm{C}$ & $\mathrm{C}$ & Schmid (1996) \\
\hline Laternula elliptica & 0.085 & 0.222 & $0.5 \pm 0.3$ & W & $\mathrm{C}$ & Ahn and Shim (1998) \\
\hline Nacella concinna & $0.039 *$ & $0.105^{*}$ & $1.0 \pm 0.5$ & $\mathrm{C}$ & $\mathrm{C}$ & Peck (1989) \\
\hline Nacella concinna & $0.095^{*}$ & $0.242^{*}$ & $-0.7 \pm 0.1$ & $\mathrm{C}$ & $\mathrm{C}$ & Peck and Veal (2001) \\
\hline \multicolumn{7}{|l|}{ Porifera } \\
\hline Cinachyra antarctica & 0.091 & 0.380 & $0.0 \pm 0.5$ & $\mathrm{M}$ & I & Present study \\
\hline Isodyctia kerguelensis & 0.027 & 0.041 & 1.0 & $\mathrm{P}$ & $\mathrm{O}$ & Kowalke (2000) \\
\hline Mycale acerata & 0.069 & 0.125 & 1.8 & $\mathrm{P}$ & $\mathrm{O}$ & Kowalke (2000) \\
\hline Stylocordyla borealis & 0.044 & 0.240 & $0.0 \pm 0.5$ & M & $\mathrm{O}$ & Present study \\
\hline Tetilla cranium & 0.352 & 0.490 & -0.5 & $\mathrm{H}$ & - & Witte and Graf (1996) \\
\hline Thenea abyssorum & 0.336 & 0.654 & -0.5 & $\mathrm{H}$ & - & Witte and Graf (1996) \\
\hline Thenea muricata & 0.186 & 0.688 & -0.5 & $\mathrm{H}$ & - & Witte and Graf (1996) \\
\hline
\end{tabular}

oxygen consumption as accurately and precisely as direct measurements of oxygen consumption (U. Witte, personal communication). We would have expected higher oxygen consumption rates for $M$. acerata and I. kerguelensis than for the species used in our experiments for two reasons: water temperature in the experiments with $M$. acerata and I. kerguelensis was up to $1.8^{\circ} \mathrm{C}$ higher than in our experiments and, secondly, especially $M$. acerata is known to be one of the few fast-growing species of Antarctic sponges (Dayton et al. 1974). However, oxygen consumption rates of $M$. acerata and I. kerguelensis are comparable to our results and five- to tenfold lower than those for the Arctic deep-sea species Thenea spp. and T. cranium. Due to the above-mentioned difficulties with the experimental setup, we think that the results for $M$. acerata and I. kerguelensis need to be interpreted with much caution.

Oxygen content inside living sponge tissue

In the second set of experiments oxygen saturation was measured inside sponge primmorphs and adult specimens. No oxygen consumption rates were determined in this experiment.

As shown in Fig. 8 oxygen saturation inside primmorphs incubated in constant flow (in a pressurized chamber), i.e. P3 and adult sponges, was much higher than in primmorphs held in stagnant water $(\mathrm{P} 1, \mathrm{P} 2)$. It could also be shown that flow speed had a distinct effect intermittent flow; and methods for oxygen determination: $C$ couloximetry; $P$ POS (standard Clarke-type); $M$ microoptode; $W$ Winkler method; $H$ oxygen consumption rates calculated from heat production data] 


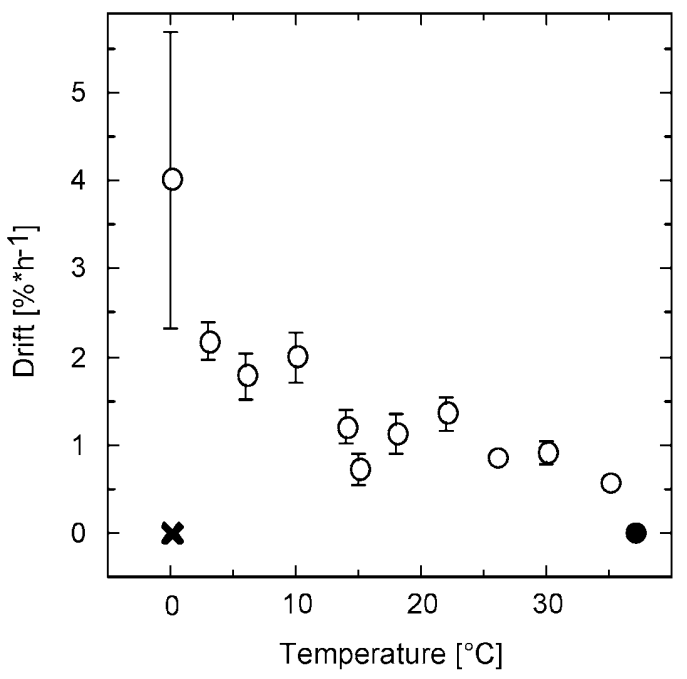

Fig. 9. Drift of oxygen sensors. Data shown are means $\pm 1 \mathrm{SE}$ for two or three sensors used in up to 36 calibration procedures (each lasting for 20-30 min) [open circle POS (polarographic oxygen sensors) O. Heilmayer and M. Langenbuch, AWI, unpublished data; filled circle POS, Baumgärtl and Lübbers (1983); cross microoptodes, maximum drift in our experiments]

on oxygen saturation inside P3 (initially: $32.7 \%$; increased flow speed: $48.3 \%$; reduced flow speed: $12.9 \%$ ). This observation corresponds well to the fact that rearing

Table 5. Comparison of different methods for measurements of oxygen saturation (or oxygen content) of water samples $(+$, feature is fully supported by method; \pm , feature is supported to some extent, e.g. depends on the precise handling of the method; -, feature is not supported by method; $\varnothing$, not applicable; $d$, discrete primmorphs outside the chamber with flow (and pressure) is much more difficult and survival rates are lower than for those reared inside the pressurized chamber (Müller, personal observation). However, pressure inside the chamber is generated with a constant flow of water. So far, it has been impossible to determine whether the differences in oxygen saturation are caused primarily by the water current, by pressure, or by a combination of both. As measurements with P3 were performed in an aquarium without extra pressure, it seems likely that flow is the more important component of the two. To further elucidate the importance of all factors, it will be necessary to perform a series of parallel experiments with a larger number of primmorphs once the difficulties in primmorph incubation have been overcome. Comparable oxygen saturation in P3 and adult sponges might indicate that water flow, which is usually generated by pumping structures, can also be applied successfully from outside. Primmorphs that have not yet developed such structures clearly suffer from oxygen depletion inside their tissues when reared without flow. Our experiments were aimed at detecting differences and testing the new method rather than carrying out a systematic investigation of flow, pressure and/or nutrients. It could be shown that microoptodes are a valuable tool to rapidly and reliably detect differences of oxygen saturation inside living sponges.

measurements; c, continuous measurements). Please note: Only selected methods have been discussed in the text explicitly. A basic description of additional methods can be found in Lampert (1984, and references therein)

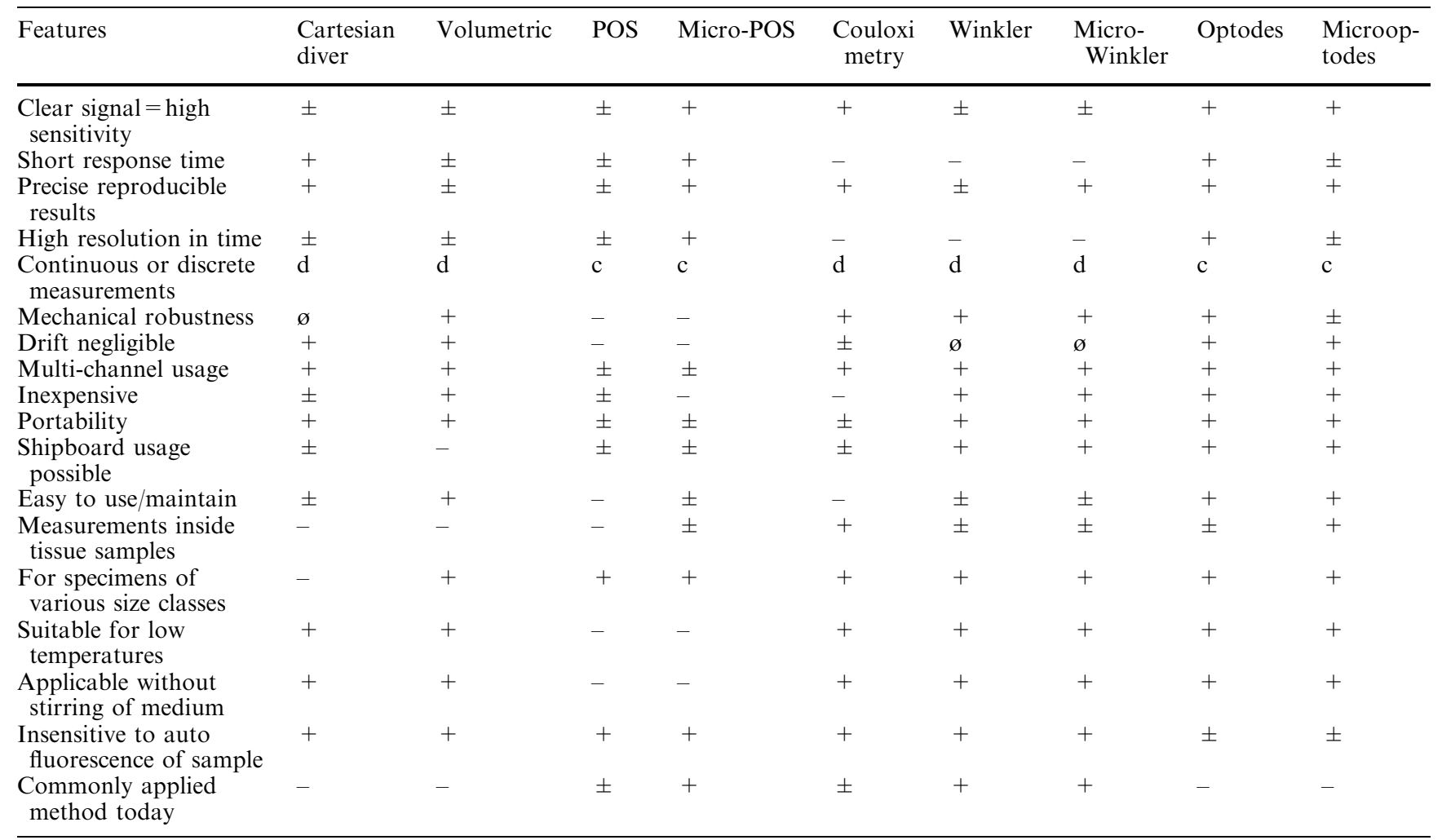


We presented two unprecedented, practical examples of applications of a new, reliable method to determine oxygen saturation in water samples as well as inside living tissue. Oxygen optodes work particularly well at low temperatures because of increased oxygen fluorescence intensity at low temperatures (Wolfbeis 1991). In our experiments oxygen optodes were easy to use and gave precise, reproducible results. We used optodes successfully in experiments lasting several days. Drift over 93 days was negligible. With the eight-channel optode array several experiments can be run simultaneously. Initially encountered problems with breaking optodes due to shearing forces upon insertion into extremely tough sponge tissue were ameliorated by mounting retractable optode tips in syringe needles (Fig. 2). The injection needle could thus be inserted into the sponge tissue first, and the optode could be pushed forward inside the injection needle and finally into the tissue itself. A comparison of the most commonly used methods to measure oxygen saturation in water samples is given in Table 5. All methods mentioned show advantageous features as well as shortcomings. The applicability of microoptodes is limited in experiments in which light plays an important role. On the one hand, photosynthesis can be enhanced by the light pulses of the optode array. On the other hand, autofluorescent samples can cause an error when the fluorescence signal is detected. These problems can be overcome by optical shielding of the optode tip, but the sensor tip will then be much larger and the spatial resolution will be greatly reduced. Nevertheless, at present, microoptodes provide the only means of precise measurements at low temperatures with high temporal resolution. Furthermore, microoptodes are cheaper than POS, and easier to handle than couloximetry. These features may be utilized in the future for in situ measurements directly comparing in- and out-flowing water (e.g. of sponges, bivalves and ascidians). It should be possible to conduct shallow water experiments with microoptodes by SCUBA diving. Moreover, optodes could also be deployed from submersibles for in situ study of the metabolic rates of deep-sea fauna.

Acknowledgements Our special thanks are extended to crew, captain and fellow scientist on board the R.V. "Polarstern" - especially the engine-room crew, without whose support the respiration experiments would not have been possible. M.P. Schodlok carried out the Winkler titrations to check calibration points. Earlier versions of the manuscript benefited from comments by B.A.B. Blu$\mathrm{hm}$, L.S. Peck and S.B. Schiel. W. Wosniok pointed out the advantages of weighted linear regression analysis. Cooperation with PreSens, Germany, was close and prolific. The authors hereby declare that experiments performed during this study comply with current German laws.

\section{References}

Ahn I-Y, Shim JH (1998) Summer metabolism of the Antarctic clam, Laternula elliptica (King and Broderip) in Maxwell Bay, King George Island and its implications. J Exp Mar Biol Ecol 224:253-264
Baumgärtl H, Lübbers DW (1983) Microcoaxial needle sensor for polarographic measurement of local $\mathrm{O}_{2}$ pressure in the cellular range of living tissue. Its construction and properties. In: Gnaiger E, Forstner H (eds) Polarographic oxygen sensors: aquatic and physiological applications. Springer, Berlin Heidelberg New York, pp 37-65

Benson BB, Krause D Jr (1984) The concentration and isotopic fractionation of oxygen dissolved in freshwater and seawater in equilibrium with the atmosphere. Limnol Oceanogr 29:620-632

Brockington S (2001) The seasonal energetics of the Antarctic bivalve Laternula elliptica (King and Broderip) at Rothera Point, Adelaide Island. Polar Biol 24:523-530

Brockington S, Peck LS (2001) Seasonality of respiration and ammonium excretion in the Antarctic echinoid Sterechinus neumayeri. Mar Ecol Prog Ser 219:159-168

Bryan JR, Riley JP, Williams PJL (1976) A Winkler procedure for making precise measurements of oxygen concentrations for productivity and related studies. J Exp Mar Biol Ecol 21:191-197

Chapelle G, Peck LS (1995) The influence of acclimation and substratum on the metabolism of the Antarctic amphipods Waldeckia obesa (Chevreux, 1905) and Bovallia gigantea (Pfeffer, 1808). Polar Biol 15:225-232

Chapelle G, Peck LS, Clarke A (1994) Effects of feeding and starvation on the metabolic rate of necrophagous Antarctic amphipod Waldeckia obesa (Chevreux, 1905). J Exp Mar Biol Ecol 183:63-76

Clark LC Jr (1956) Monitor and control of blood and tissue oxygen tensions. Trans Am Soc Artificial Internal Organs 2:41-46

Clarke A (1983) Life in cold water: the physiological ecology of polar marine ectotherms. Oceangr Mar Biol Annu Rev 21:341-453

Culberson CH (1991) Dissolved oxygen. WOCE operations manual 3, section 3.1, WOCE Hydrographic Programme. WOCE, Woods Hole, Mass. http://whpo.ucsd.edu/manuals.htm

Dayton PK, Robilliard GA, Paine RT, Dayton LB (1974) Biological accommodation in the benthic community at McMurdo Sound, Antarctica. Ecol Monogr 44:105-128

Dickson (1996) Determination of dissolved oxygen in seawater by Winkler titration. WOCE operations manual 3, section 3.1, WOCE Hydrographic Programme. WOCE, Woods Hole, Mass. http://whpo.ucsd.edu/manuals.htm

Draper NR, Smith H (1980) Applied regression analysis. Wiley, New York

Glud RN, Klimant I, Holst G, Kohls O, Meyer V, Kühl M, Gundersen JK (1999) Adaptation, test and in situ measurements with $\mathrm{O}_{2}$ microopt(r)odes on benthic landers. Deep-Sea Res I 46:171-183

Holst G, Glud RN, Kühl M, Klimant I (1997) A microoptode array for fine-scale measurement of oxygen distribution. Sensors and Actuators B 38-39:122-129

Hummel H, Sepers ABJ, de Wolf L, Melissen FW (1988) Bacterial growth on the marine sponge Halichondria panicea induced by reduced waterflow rate. Mar Ecol Prog Ser 42:195-198

Klimant I, Meyer V, Kühl M (1995) Fiber-optic oxygen microsensors, a new tool in aquatic biology. Limnol Oceanogr 40:1159-1165

Klimant I, Kühl M, Glud RN, Holst G (1997) Optical measurement of oxygen and temperature in microscale: strategies and biological implications. Sensors and Actuators B 38:29-37

Kowalke J (2000) Ecology and energetics of two Antarctic sponges. J Exp Mar Biol Ecol 247:85-97

Krasko A, Schröder HC, Perovic S, Steffen R, Kruse M, Reichert W, Müller IM, Wüller WEG (1999) Ethylen modulates gene expression in cells of the marine sponge Suberites domuncula and reduces the degree of apoptosis. J Biol Chem 274:3152431530

Lampert W (1984) The measurement of respiration. In: Downing JA, Rigler FH (eds) A manual for the assessment of secondary production in fresh waters, IBP handbook 17. Blackwell, Oxford, pp 413-468

Langdon C (1984) Dissolved oxygen monitoring system using a pulsed electrode: design, performance, and evaluation. DeepSea Res 31:1357-1367 
Leichter JJ, Witman JD (1997) Water flow over subtidal rock walls: relation to distributions and growth rates of sessile suspension feeders in the Gulf of Maine. Water flow and growth rates. J Exp Mar Biol Ecol 209:293-307

Müller WEG, Wiens M, Batel R, Steffen R, Schröder HC, Borojevic R, Custodio MR (1999) Establishment of a primary cell culture from a sponge: primmorphs from Suberites domuncula. Mar Ecol Prog Ser 178:205-219

Paine RT (1964) Ash and calorie determinations of sponge and opisthobranch tissues. Ecology 45:384-387

Peck LS (1989) Temperature and basal metabolism in two Antarctic marine herbivores. J Exp Mar Biol Ecol 127:1-12

Peck LS, Conway LZ (2000) The myth of metabolic cold adaptation: oxygen consumption in stenothermal Antarctic bivalves. In: Harper E, Taylor JD, Crame AJ (eds) The evolutionary ecology of bivalve molluses, special publication 177. London Geological Society, London, pp 441-450

Peck LS, Uglow RF (1990) Two methods for the assessment of the oxygen content of small volumes of seawater. J Exp Mar Biol Ecol 141:53-62

Peck LS, Veal R (2001) Feeding, metabolism and growth in the Antarctic limpet, Nacella concinna (Strebel, 1908). Mar Biol 138:553-560

Propp MV, Garber MR, Ryabuscko VI (1982) Unstable processes in the metabolic rate measurement in flow-through systems. Mar Biol 67:47-49
Revsbech NP, Jørgensen BB, Blackburn HT, Cohen Y (1983) Microelectrode studies of the photosynthesis and $\mathrm{O}_{2}, \mathrm{H}_{2} \mathrm{~S}$ and $\mathrm{pH}$ profiles of a microbial mat. Limnol Oceanogr 28:1062-1074

Roland F, Caraco NF, Cole JJ, Giorgio Pd (1999) Rapid and precise determination of dissolved oxygen by spectrophotometry: evaluation of interference from color and turbidity. Limnol Oceanogr 44:1148-1154

Schmid MK (1996) Zur Verbreitung und Respiration ökologisch wichtiger Bodentiere in den Gewässern um Svålbard (Arktis). Ber Polarforsch 202:1-93

Stefansson E, Peterson JI, Wang YH (1989) Intraocular oxygen tension measured with a fiber-optic sensor in normal and diabetic dogs. Am J Physiol 256:1127-1133

Stokes MD, Somero GN (1999) An optical oxygen sensor and reaction vessel for high-pressure applications. Limnol Oceanogr 44:189-195

Wilson TRS, Cussen H, Braithwaite AC (1993) An improved electrode for pore water oxygen measurement in ocean sediments. Sci Total Environ 135:115-121

Winkler LW (1888) The determination of dissolved oxygen in water. Ber Dtsch Chem Ges 21:2843-2846

Witte U, Graf G (1996) Metabolism of deep-sea sponges in the Greenland-Norwegian Sea. J Exp Mar Biol Ecol 198:223-235

Wolfbeis OS (1991) Oxygen sensors. In: Wolfbeis OS (ed) Fiber optic chemical sensors. CRC, Boca Raton, Fla., pp 19-5 